\title{
Hepatic pseudolymphoma: a clinicopathological study of five cases and review of the literature
}

\author{
Yoh Zen ${ }^{1,2}$, Takahiko Fujiii and Yasuni Nakanuma ${ }^{2}$ \\ ${ }^{1}$ Institute of Liver Studies, King's College Hospital, London, UK and ${ }^{2}$ Department of Human Pathology, \\ Kanazawa University Graduate School of Medicine, Kanazawa, Japan
}

\begin{abstract}
Hepatic pseudolymphoma is a rare and controversial condition, the clinicopathological characteristics of which have not been well documented. In this study, we retrospectively examined clinical and pathological features of five patients (two males and three females, 40-81 years old) with hepatic pseudolymphoma. Two patients had multiple lesions (two lesions each). Three patients had histories of chronic liver disorders, including primary biliary cirrhosis, nonalcoholic steatohepatitis, and chronic viral hepatitis B. Tumor sizes ranged from 0.5 to $5.5 \mathrm{~cm}$ in diameter (average, $2.1 \mathrm{~cm}$ ). Histologically, hepatic pseudolymphoma consisted of tumorous infiltrates of mature lymphocytes with multiple lymph follicles or clusters of epithelioid histiocytes. Lymphocytes characteristically extended into nearby portal tracts. Ductal structures positive for cytokeratin 7 were entrapped in the peripheral parts of nodules. In situ hybridization of immunoglobulin light chains revealed $B$ lymphocytes and plasma cells to be polyclonal. In addition, clonal rearrangements of immunoglobulin heavy chains could not be shown in any cases using PCR. Two patients were diagnosed by needle biopsy. Interestingly, their nodules spontaneously diminished in size without any treatment. Malignant transformation was not observed in any cases during the follow-up periods. In conclusion, this study revealed that hepatic pseudolymphoma had benign behavior. The diagnosis of hepatic pseudolymphoma can be challenging especially with biopsied specimens, but could be aided by a characteristic growth pattern, in situ hybridization, analyses of gene rearrangements, or a follow-up based on images.
\end{abstract}

Modern Pathology (2010) 23, 244-250; doi:10.1038/modpathol.2009.165; published online 13 November 2009

Keywords: liver; lymphoma; reactive lymphoid hyperplasia

Nodular reactive lymphoid proliferation has been called pseudolymphoma or reactive lymphoid hyperplasia. ${ }^{1}$ New techniques such as in situ hybridization and the analysis of gene rearrangements have revealed some lesions previously diagnosed as pseudolymphomas to be clonal proliferations of lymphocytes. ${ }^{2}$ The concept of a marginal-zone B-cell lymphoma of the MALT type is now being considered for such lesions., ${ }^{3,4}$ Moreover, pseudolymphoma is still an established disease entity. ${ }^{5}$ Hepatic pseudolymphoma is an extremely rare condition, with most reports to date dealing with single cases. ${ }^{6-24}$ Therefore, the pathogenesis and

Correspondence: Dr Yoh Zen, MD, Institute of Liver Studies, King's College Hospital, Denmark Hill, London SE5 9RS, UK. E-mail: yoh.zen@kcl.ac.uk

Received 19 July 2009; revised 3 September 2009; accepted 21 October 2009; published online 13 November 2009 clinical implications of hepatic pseudolymphoma have not been well documented.

We studied five patients with hepatic pseudolymphoma to reveal the clinicopathological characteristics of this controversial disease entity.

\section{Patients and methods}

Patients

Five patients originally diagnosed with hepatic pseudolymphoma were selected from the histopathology files of Kanazawa University Hospital in Japan and consultation files of the authors. All patients were diagnosed from 1992 to 2009. Average age at the time of diagnosis was 63 years (range 4081). There were three women and two men. Three patients underwent surgical resection of tumor masses and in two instances material was obtained 
with liver biopsy. One case (patient 1) was previously reported. ${ }^{24}$

\section{Histological Examinations}

After a macroscopic examination of the explanted livers, tissue blocks were sampled from nodular lesions and background livers. The sampled tissue and needle biopsied tissue were fixed in neutral formalin, and embedded in paraffin. Sections $(4 \mu \mathrm{m})$ were cut from each paraffin block, and stained with hematoxylin and eosin or reticulin. Additional sections were saved for immunohistochemistry.

\section{Immunohistochemistry}

Representative blocks were chosen for immunohistochemistry in each case. Immunostaining of CD3, CD20, CD79 $\alpha$, cytokeratin 7 (CK7), or immunoglobulin G4 (IgG4) was performed by an autostainer (HX System Benchmark, Ventana Medical Systems, Tucson, AZ, USA). Primary antibodies used were a rabbit monoclonal antibody for human CD3 (LAB VISION corporation, Fremont, CA, USA), a rabbit monoclonal antibody for human CD20 (Abcam, Tokyo, Japan), a mouse monoclonal antibody for CD79 $\alpha$ (Dako Cytomation, Glostrup, Denmark), a mouse monoclonal antibody for CK7 (Dako Cytomation), and a mouse monoclonal antibody for human IgG4 (ZYMED Laboratory, San Francisco, CA, USA). Sections were pretreated with a heated plate (for CD3, CD20, and CD79 $\alpha$ ) or proteinase (for IgG4). Negative controls were evaluated by substituting the primary antibody with similarly diluted nonimmunized mouse serum.

\section{In situ Hybridization}

The in situ hybridization of $\kappa$ - and $\lambda$-chains was performed by an autostainer (HX System Bench- mark, Ventana Medical Systems) as per the manufacturer's instructions. Specific probes for $\kappa$-chain and $\lambda$-chain were obtained from Ventana Medical Systems. We used specimens of gastric marginalzone B-cell lymphoma (MALToma) for a positive control and those of tonsillitis for a negative control.

\section{Gene Rearrangement Analysis}

PCR was used to investigate the arrangement of the immunoglobulin heavy chain gene with DNA templates obtained from the paraffin-embedded specimens. Gene rearrangements were examined by semi-nested PCR using five primers: FR3A $5^{\prime}$-CT GTCGACACGGC(T/C)(G/C)TGTATTACTG-3'; LJH, 5'-AACTGCAGAGGAGACGGTGACC-3'; VLJH, 5'-G TGACCAGGGT(A/G/C/T)CCTTGGCCCCAG-3'; $\mathrm{VH}_{1-5}$, 5'-AAGCTTGTGACCAGGGT(G/T/C)CC(T/C)TGGCC CCAG-3'; $\mathrm{VH}_{6}, 5^{\prime}$-AAGCTTGTGACCGTGGTCCCTT GCCCCCAG-3'. Two sets of semi-nested PCR were performed as follows: Set 1, outer nest FR3A-LJH, inner nest FR3A-VLJH; Set 2, outer nest FR3A-VJH, inner nest FR3A-mixed $\mathrm{VH}_{1-5} / \mathrm{VH}_{6}$. Tissue samples of B-cell lymphoma were used as positive controls and those without lymphomatous lesions as negative controls. After PCR, the amplified products were analyzed on $4.5 \%$ agarose gels.

\section{Results}

\section{Clinical Features}

Clinical features of five patients are listed in Table 1. Two patients were incidentally found to have nodular lesions in the liver during a work-up for diabetes mellitus (patient 1) and Takayasu's arteritis or anti-phospholipid syndrome (patient 5). Patient 2 had been followed up for primary biliary cirrhosis, diagnosed on the basis of a needle biopsy 9 years before. Similarly, patient 3 had a history of chronic viral hepatitis B. Patient 4 was referred to hospital

Table 1 Clinical characteristics of patients examined in this study

\begin{tabular}{|c|c|c|c|c|c|c|c|}
\hline Patient & $\begin{array}{c}\text { Age } \\
\text { (years) }\end{array}$ & Gender & Past history & $\begin{array}{l}\text { No. of } \\
\text { lesions }\end{array}$ & Size (in $\mathrm{cm}$ ) & Location & $\begin{array}{l}\text { Operation/ } \\
\text { biopsy }\end{array}$ \\
\hline 1 & 66 & $\mathrm{~F}$ & $\begin{array}{l}\text { Nonalcoholic } \\
\text { steatohepatitis, diabetes } \\
\text { mellitus }\end{array}$ & 1 & 1.5 & Right lobe & Partial resection \\
\hline 2 & 63 & $\mathrm{~F}$ & $\begin{array}{l}\text { Primary biliary cirrhosis, } \\
\text { chronic thyroiditis, } \\
\text { adrenocortical adenoma }\end{array}$ & 2 & $0.9,0.5$ & S7, S6 & Partial resection \\
\hline 3 & 40 & M & Chronic viral hepatitis B & 1 & 2.0 & S6 & Partial resection \\
\hline 4 & 81 & M & $\begin{array}{l}\text { Cholecystolithiasis, no } \\
\text { liver disease }\end{array}$ & 1 & 5.5 & S3 & Needle biopsy \\
\hline 5 & 64 & $\mathrm{~F}$ & $\begin{array}{l}\text { Takayasu aortitis, } \\
\text { antiphospholipid } \\
\text { syndrome, no liver } \\
\text { disease }\end{array}$ & 2 & $3.5,1.0$ & S5, S7 & Needle biopsy \\
\hline
\end{tabular}

F, female; M, male; S, segment. 
with abdominal pain, where ultrasonography and computed tomography revealed a hepatic nodular lesion, as well as cholecystolithiasis. Patients 2 and 5 had two lesions. The remaining three patients had a single nodular lesion. Interestingly, all lesions except the one in patient 4 were in the right lobe. Tumor sizes ranged from 0.5 to $5.5 \mathrm{~cm}$ in diameter (average $2.1 \mathrm{~cm}$ ). A total of four lesions were surgically resected from patients 1-3. Needle biopsies were performed in cases 4 and 5 (the larger lesion of patient 5). Those liver specimens from six lesions were used in the following analyses.

\section{Pathological Features}

Macroscopically, surgically resected specimens showed vaguely nodular, homogeneous, gray lesions. Histologically, all six lesions showed a nodular proliferation of mature small lymphocytes. Lymph follicles with germinal centers were well formed in all cases (Figure 1). In interfollicular areas, several histiocytes and immunoblasts were also identified. Clusters of epithelioid histiocytes without necrosis were observed in the lesions of patients 1 and 3. Multinucleated giant cells in a granulomatous reaction contained cholesterin clefts (patient 1). Small calcifications were also identified in patient 3. No atypical cells suggestive of neoplasia were identified in any lesions examined (Figure 2). Bile ducts were identified within the nodules, especially at the periphery. Ductal structures were angulated and surrounded by lymphocytes; however, characteristic lymphoepithelial lesions could not be identified. Interestingly, lymphocytic infiltration extended along portal tracts around all lesions (Figure 3). In addition, a capsule-like fibrous structure was partially identified around the lesion in patient 3 . The two lesions in patient 2 showed

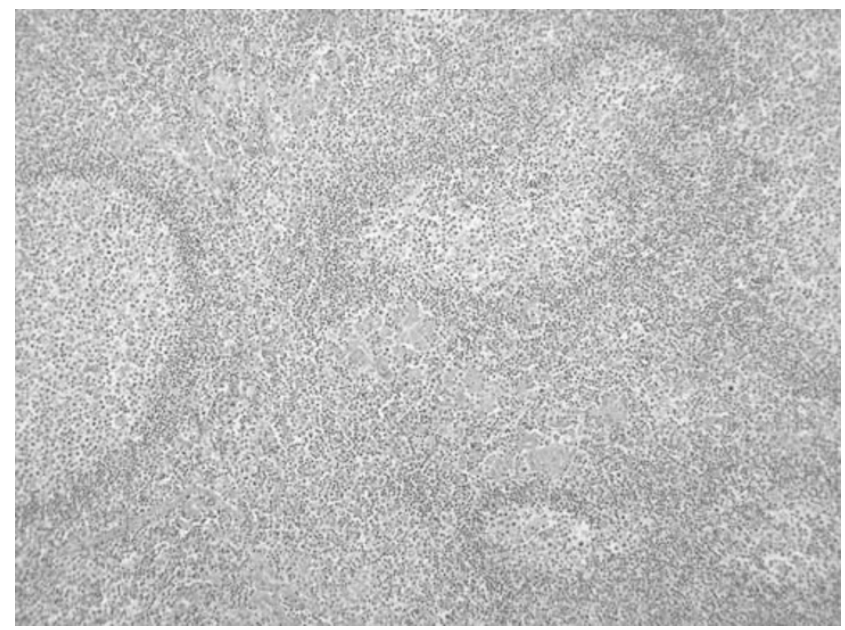

Figure 1 Histopathology of hepatic pseudolymphoma. Nodular infiltration by lymphocytes with the formation of lymphoid follicles is observed. Epithelioid cells cluster in the interfollicular area. H\&E, original magnification: $\times 100$. similar histological features. Needle biopsies of cases 4 and 5 revealed the characteristic feature of a hepatic parenchyma divided by broad areas of lymphocytic infiltration, in which small bile ducts were entrapped (Figure 4). These features seemed to correspond to the edge of nodular lesions in surgical cases.

In the background liver, patient 1 showed steatosis, hepatocellular ballooning, and some Mallory bodies. These histological features were consistent with nonalcoholic steatohepatitis. In patient 2 , the background liver showed portal fibrosis with bile duct damage and cholangitis, all of which corresponded to primary biliary cirrhosis, stage 2 . Patient 3 showed chronic hepatitis B with focal interface hepatitis. Patients 4 and 5 showed only focal steatosis in the background livers.

\section{Immunohistochemical Analysis and In Situ Hybridization}

Lymphocytes within all lesions were composed of CD3-positive $\mathrm{T}$ cells and CD20/CD79 $\alpha$-positive B cells (Figure 5). $\mathrm{T}$ and $\mathrm{B}$ cells were regularly distributed. IgG4-positive cells were scarce in all lesions. Immunostaining of CK7 revealed irregularly distributed CK7-positive ductal structures especially at the periphery of each nodule (Figure 5). In situ hybridization of immunoglobulin light chains revealed the polyclonal nature of plasma cells in all lesions (Figure 6).

\section{Analysis of Gene Rearrangements}

A PCR analysis of the immunoglobulin heavy chain gene did not show clonal rearrangements in any liver specimens (Figure 7).

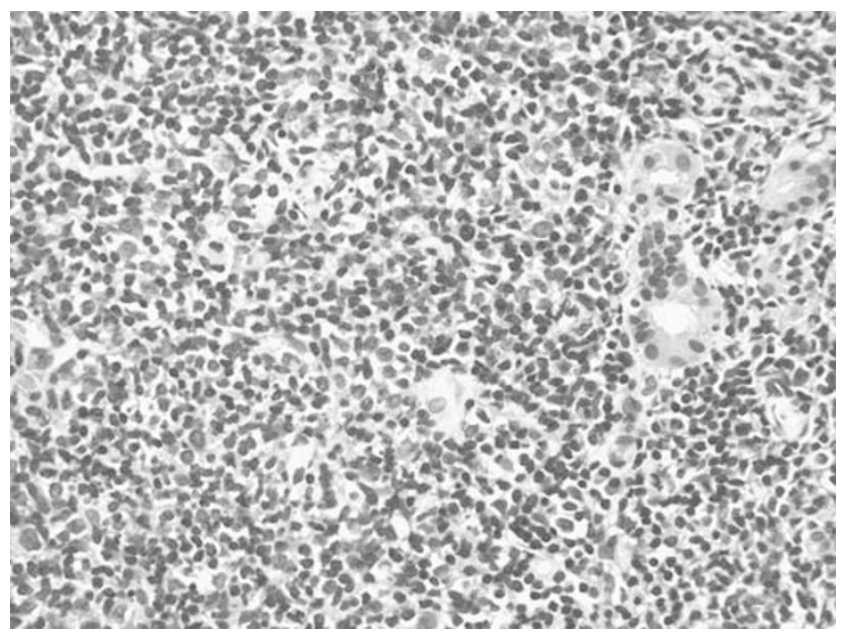

Figure 2 Histopathology of hepatic pseudolymphoma. Lymphocytes within a lesion are mainly small and appear mature with scattered medium and large cells. They have round nuclei with scant cytoplasm and do not show any atypical features. H\&E, original magnification: $\times 400$. 

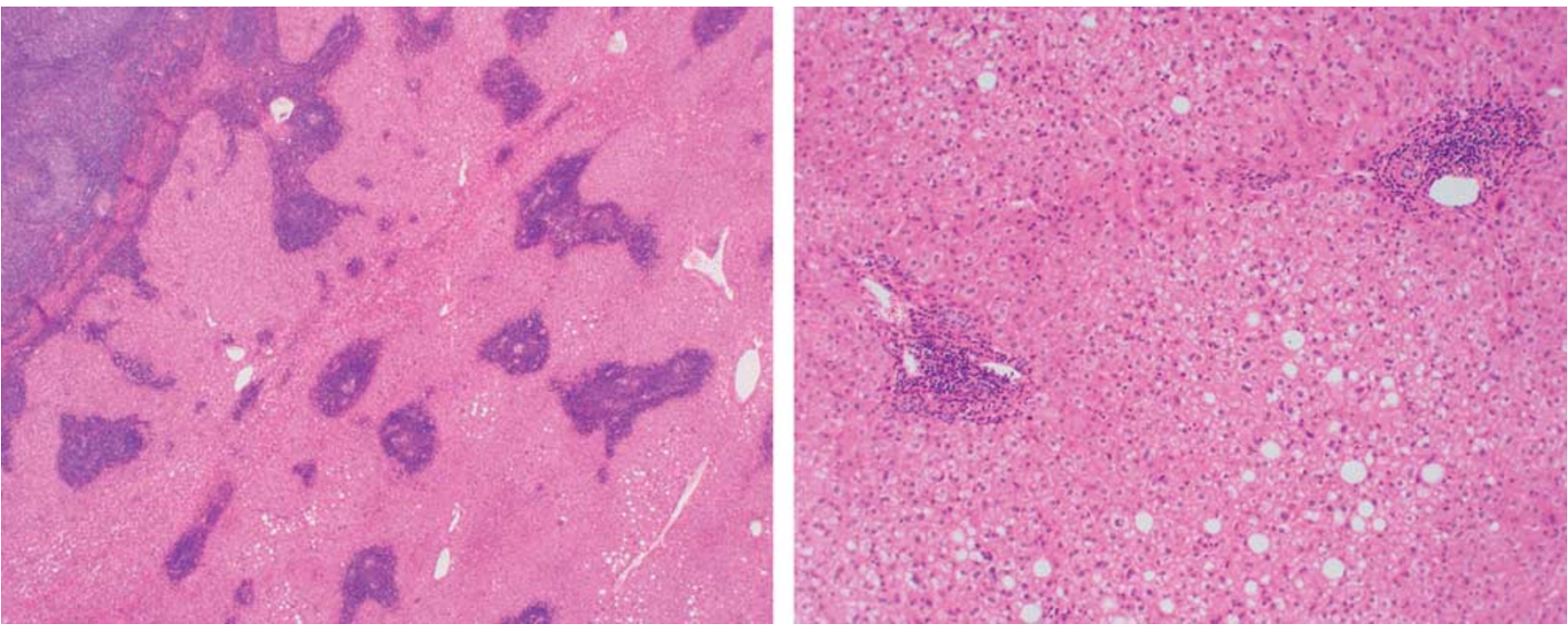

Figure 3 Histopathology of hepatic pseudolymphoma. At the edge of the nodule, lymphocytic infiltration extends into perinodular portal tracts (left). Compared with the background liver with chronic hepatitis B (right), lymphocytic infiltration is more pronounced in the portal tracts around the nodule (left). H\&E, original magnification: left $\times 20$; right $\times 100$.

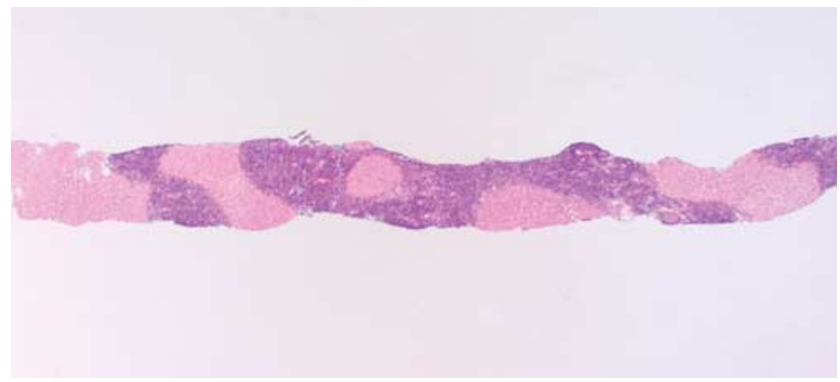

Figure 4 Histopathology of hepatic pseudolymphoma (a needle biopsy case). Hepatic parenchyma is divided by broad lymphocytic infiltration, in which bile ducts can be identified. H\&E, original magnification: $\times 20$.

\section{Follow-Up Data}

Patient 1 was found to have three nodular lesions 6 years after a surgical resection of pseudolymphoma. The three lesions were diagnosed as hepatocellular carcinomas (two lesions) and a dysplastic lesion by needle biopsies. There was no recurrence of the pseudolymphoma during the follow-up for 10 years. Similarly, no recurrence of lymphoproliferative lesions was identified in the other two surgical cases during the follow-up periods after surgical resection (15 months for patient 2 and 30 months for patients 3). After the diagnosis by needle biopsy, two patients were followed up for 6 months (patient 4) and 36 months (patient 5) without any treatments. Interestingly, nodules in those two cases gradually decreased in size on radiological images. In patient 4 , the nodule decreased in diameter from 5.5 to $3.5 \mathrm{~cm}$. The larger nodule in patient 5 decreased from 3.5 to $1.5 \mathrm{~cm}$. Similarly, the smaller nodule, which was not biopsied, became inconspicuous on follow-up images. No patients were found to have malignant lymphomas at any sites, including the extrahepatic organs and lymph nodes during the follow-up periods.

\section{Discussion}

Hepatic pseudolymphoma is an extremely rare condition and most reports on it have been case reports. In 1999, Sharifi et a ${ }^{13}$ reported three cases of pseudolymphoma, the largest series until now. All cases reported in English are reviewed in Table $2 .^{6-24}$ The total number of cases was 26, including 5 patients in the current study. Five patients $(19 \%)$ had multiple (two or three) lesions. In total, 32 lesions were summarized. The youngest patient is a 15-year-old female, who had primary immunodeficiency. Except for that case, all patients were adults (36-85 years old). Interestingly, $82 \%$ of patients were female. In all, $60 \%$ of the lesions developed in the right hepatic lobe. The average diameter was $1.7 \mathrm{~cm}$. Regarding background liver disease, $27 \%$ had chronic liver disorders. In addition, $23 \%$ of patients had autoimmune disorders in extrahepatic organs. Interestingly, $23 \%$ of patients had histories of malignancy, including gastric, colon, and renal cell cancers. Malignant transformation was not observed in any cases.

The pathogenesis of hepatic pseudolymphoma is still unknown, though it might involve infectious or autoimmune reactions..$^{25,26}$ The relatively high prevalence of autoimmune disorders suggests a possible involvement of autoimmunity to hepatic pseudolymphoma. In addition, the association with gastrointestinal malignancies suggests that antigens coming from the gastrointestinal tract through portal veins participate in the pathogenesis. However, the association with autoimmune or neoplastic 

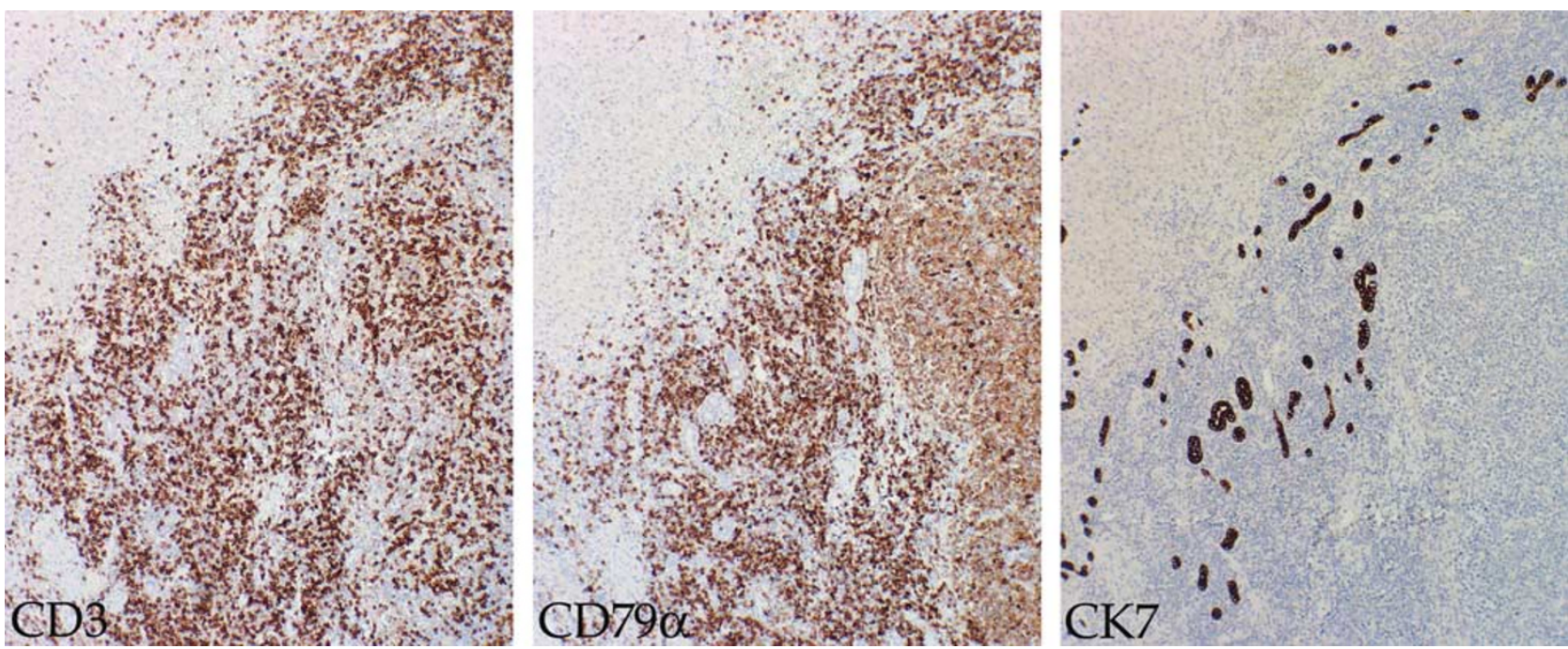

Figure 5 Immunostaining of CK7 in hepatic pseudolymphoma. Lymphocytes within the nodule consist of T cells (positive for CD3) and B cells (positive for CD79 $\alpha$ ). Ductal structures positive for CK7 are observed at the periphery of the nodule. All, original magnification: $\times 100$.
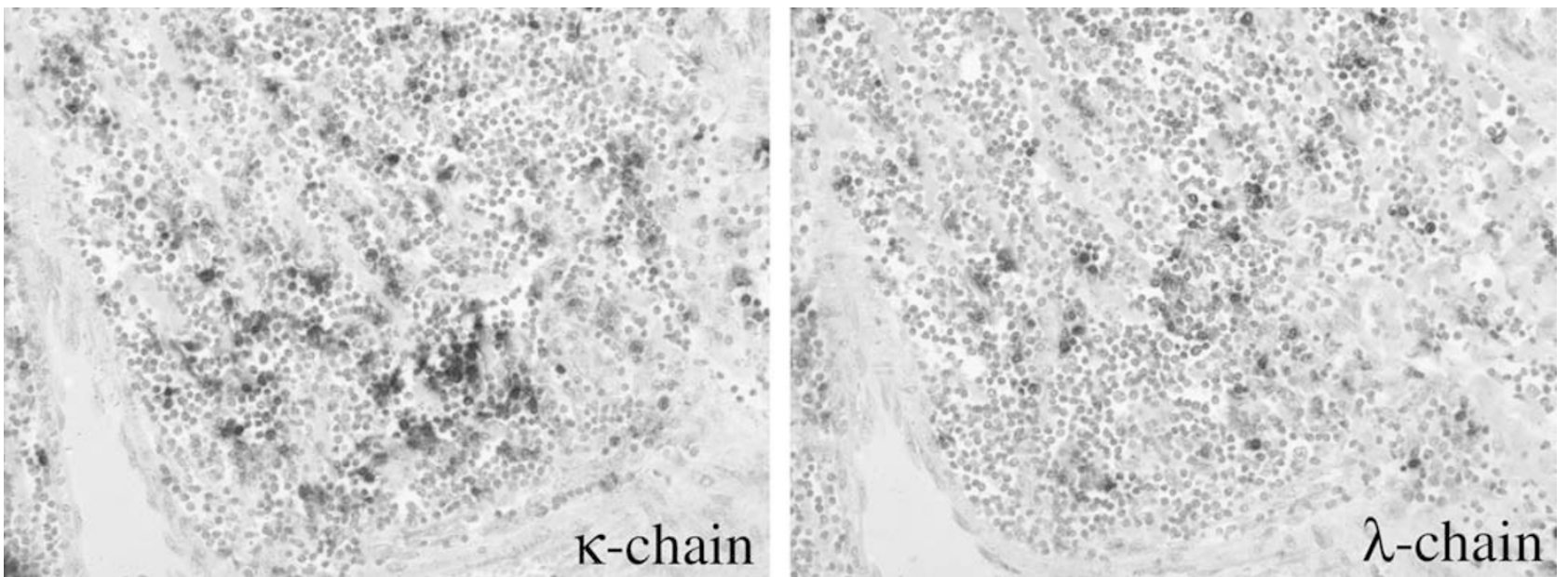

Figure 6 In situ hybridization of immunoglobulin light chains. The $\kappa$-positive and $\lambda$-positive cells are intermixed in this field. Original magnification: $\times 400$.

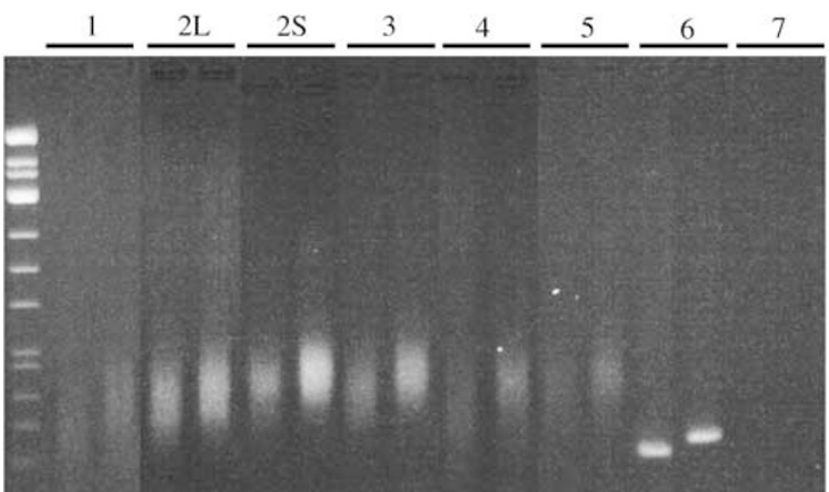

Figure 7 Immunoglobulin heavy chain gene rearrangements. Clonal rearrangement was not observed in any case. Lane 1 patient 1; lane $2 \mathrm{~L}$, the larger lesion in patient 2 ; lane $2 \mathrm{~S}$, the smaller lesion in patient 2; lane 3, patient 3; lane 4, patient 4; lane 5 , patient 5; lane 6, positive control; and lane 7, negative control. Each case was examined with two sets of primers (left, FR3A-LJH, FR3A-VLJH; right, FR3A-LJH, FR3A-VH1-5/VH6). conditions might merely reflect the fact that patients frequently undergo abdominal examinations using radiological images. Half of the previous reports were published after 2006. This is probably related to recent advances in imaging devices. Therefore, hepatic pseudolymphoma might be detected more in the future.

Making a diagnosis of pseudolymphoma by needle biopsy can be challenging. In situ hybridization of light-chain immunoglobulins and analyses of gene rearrangements can also be useful. In addition, two needle biopsy cases examined in this study revealed a characteristic pattern of infiltration by lymphocytes at the edge of nodules. Broad areas of infiltration divided the hepatic parenchyma. The hepatocytes formed hepatocellular islands within the lymphoid stroma. This might be another feature useful for the diagnosis. Immunochemistry of CK7 showed many entrapped bile ducts within and at 
Table 2 Review of the literature regarding hepatic pseudolymphoma

\begin{tabular}{|c|c|}
\hline Total number of cases & 26 \\
\hline Total number of lesions & 32 \\
\hline Age (average and range) & 58 years $(15-81)$ \\
\hline Gender (male, female) & $18,82 \%$ \\
\hline Location (right; left; caudate lobes) & $15 ; 9 ; 1^{\mathrm{a}}$ \\
\hline Size (average and range) & $1.7 \mathrm{~cm}(0.5-5.5)$ \\
\hline Multiple lesions & $19 \%$ ( 2 or 3 lesion \\
\hline Chronic liver diseases & $27 \%$ \\
\hline Primary biliary cirrhosis ${ }^{13}$ & Patient 2 \\
\hline Chronic viral hepatitis ${ }^{9,11}$ & Patient 3 \\
\hline Nonalcoholic steatohepatitis & Patient 1 \\
\hline $\begin{array}{l}\text { Nodular and neoplastic liver lesions } \\
\text { Focal nodular hyperplasia }^{16} \\
\text { Cavernous hemangioma }^{16}\end{array}$ & $4 \%$ \\
\hline $\begin{array}{l}\text { Extrahepatic autoimmune disorders } \\
\text { Sjögren syndrome }{ }^{14}\end{array}$ & $23 \%$ \\
\hline Hashimoto's thyroiditis ${ }^{12,21}$ & Patient 2 \\
\hline Takayasu aortitis & Patient 5 \\
\hline Antiphospholipid syndrome & Patient 5 \\
\hline CREST syndrome $^{13}$ & \\
\hline $\begin{array}{l}\text { Carcinoma } \\
\text { Gastric cancer }{ }^{7,17} \\
\text { Colorectal cancer }^{17,18,23} \\
\text { Renal cell carcinoma }^{22}\end{array}$ & $23 \%$ \\
\hline
\end{tabular}

CREST, calcinosis, Raynaud's phenomenon, esophageal dysmotility, sclerodactyly, and telangiectasia.

${ }^{\mathrm{a}}$ Data available in only 25 lesions.

the edge of nodules. This result suggests that pseudolymphoma is derived from lymphoid tissue related to a portal tract, and could be enlarged by involving nearby portal tracts.

It is important to distinguish hepatic pseudolymphoma from low-grade lymphoma. ${ }^{27}$ Lymphoepithelial lesions and cellular atypia are important to be a differential diagnosis. It is rare to diagnose low-grade B-cell lymphoma by needle liver biopsy because of the infrequent hepatic involvement. Until now, we diagnosed only two cases of B-cell chronic lymphocytic leukemia (B-CLL) on a needle biopsy. Both showed portal distribution of atypical lymphoid cells without nodule formation. Two previous studies examined patterns of hepatic infiltration in malignant lymphoma. ${ }^{28,29}$ The studies examined 294 cases in total, including 76 cases of low-grade B-cell lymphomas (marginal-zone B-cell lymphoma, B-CLL, mantle cell lymphoma, and follicular lymphoma). ${ }^{28,29}$ The patterns of hepatic infiltration were classified into nodular, portal, and sinusoidal. Interestingly, combined results of both studies, most of low-grade B-cell lymphomas showed a predominantly portal infiltration pattern with or without sinusoidal infiltration. A nodular infiltration pattern like hepatic pseudolymphoma was identified in 15 of 76 cases $(20 \%))^{28,29}$ Interestingly, marginal-zone B-cell lymphoma, the most important differential diagnosis of hepatic pseudolymphoma, showed this pattern in only one case
(6\% of 16 cases). ${ }^{28,29}$ It is still ambiguous whether or not a characteristic pattern of infiltration at the edge of hepatic pseudolymphoma can be observed in low-grade B-cell lymphoma. But, unique features observed in needle biopsies (Figure 4) was not described in those two studies. These data suggest that infiltration patterns could be helpful to discriminate hepatic pseudolymphoma from low-grade B-cell lymphoma.

Most hepatic pseudolymphomas have been treated surgically because of difficulties with the diagnosis by needle biopsy. In 2006, Ota et $a l^{15}$ reported a patient with hepatic pseudolymphoma diagnosed by needle biopsy and followed up without surgical resection. In that report, the nodular size decreased from 1.6 to $0.8 \mathrm{~cm}$ during the follow-up for 18 months. Similarly, patients 4 and 5 in the current study also showed spontaneous regression. We first detected a decrease in tumor size at 2 and 4 months.

In conclusion, this study revealed that hepatic pseudolymphoma shows benign behavior. The diagnosis of hepatic pseudolymphoma can be challenging but might be aided by in situ hybridization, analyses of gene rearrangements, or follow-up based on images.

\section{Disclosure/conflict of interest}

The authors declare no conflict of interest.

\section{References}

1 Tokunaga O, Watanabe T, Morimatsu M. Pseudolymphoma of the stomach. A clinicopathologic study of 15 cases. Cancer 1987;59:1320-1327.

2 Schulman H, Sickel J, Kleinman MS, et al. Gastric 'pseudolymphoma' with restricted light chain expression in a patient with obscure gastrointestinal blood loss. Dig Dis Sci 1991;36:1495-1499.

3 Zukerberg LR, Ferry JA, Southern JF, et al. Lymphoid infiltrates of the stomach. Evaluation of histologic criteria for the diagnosis of low-grade gastric lymphoma on endoscopic biopsy specimens. Am J Surg Pathol 1990;14:1087-1099.

4 Abbondanzo SL, Sobin LH. Gastric 'pseudolymphoma': a retrospective morphologic and immunophenotypic study of 97 cases. Cancer 1997;79:1656-1663.

5 Kazakov DV, Burg G, Dummer R, et al. Cutaneous lymphomas and pseudolymphomas: newly described entities. Recent Results Cancer Res 2002;160:283-293.

6 Snover DC, Filipovich AH, Dehner LP, et al. Pseudolymphoma. A case associated with primary immunodeficiency disease and polyglandular failure syndrome. Arch Pathol Lab Med 1981;105:46-49.

7 Grouls V. Pseudolymphoma (inflammatory pseudotumor) of the liver. Zentralbl Allg Pathol 1987; 133:565-568.

8 Isobe H, Sakamoto S, Sakai H, et al. Reactive lymphoid hyperplasia of the liver. J Clin Gastroenterol 1993;16:240-244. 
9 Ohtsu T, Sasaki Y, Tanizaki H, et al. Development of pseudolymphoma of liver following interferonalpha therapy for chronic hepatitis B. Intern Med 1994;33:18-22.

10 Tanizawa T, Eishi Y, Kamiyama R, et al. Reactive lymphoid hyperplasia of the liver characterized by an angiofollicular pattern mimicking Castleman's disease. Pathol Int 1996;46:782-786.

11 Kim SR, Hayashi Y, Kang KB, et al. A case of pseudolymphoma of the liver with chronic hepatitis C. J Hepatol 1997;26:209-214.

12 Nagano K, Fukuda Y, Nakano I, et al. Reactive lymphoid hyperplasia of liver coexisting with chronic thyroiditis: radiographical characteristics of the disorder. J Gastroenterol Hepatol 1999;14: 163-167.

13 Sharifi S, Murphy M, Loda M, et al. Nodular lymphoid lesion of the liver: an immune-mediated disorder mimicking low-grade malignant lymphoma. Am J Surg Pathol 1999;23:302-308.

14 Okubo H, Maekawa H, Ogawa K, et al. Pseudolymphoma of the liver associated with Sjögren's syndrome. Scand J Rheumatol 2001;30:117-119.

15 Ota H, Isoda N, Sunada F, et al. A case of hepatic pseudolymphoma observed without surgical intervention. Hepatol Res 2006;35:296-301.

16 Willenbrock K, Kriener S, Oeschger S, et al. Nodular lymphoid lesion of the liver with simultaneous focal nodular hyperplasia and hemangioma: discrimination from primary hepatic MALT-type non-Hodgkin's lymphoma. Virchows Arch 2006;448:223-227.

17 Sato K, Ueda Y, Yokoi M, et al. Reactive lymphoid hyperplasia of the liver in a patient with multiple carcinomas: a case report and brief review. J Clin Pathol 2006;59:990-992.

18 Takahashi H, Sawai H, Matsuo Y, et al. Reactive lymphoid hyperplasia of the liver in a patient with colon cancer: report of two cases. BMC Gastroenterol 2006;6:25.

19 Maehara N, Chijiiwa K, Makino I, et al. Segmentectomy for reactive lymphoid hyperplasia of the liver: report of a case. Surg Today 2006;36:1019-1023.

20 Matsumoto N, Ogawa M, Kawabata M, et al. Pseudolymphoma of the liver: sonographic findings and review of the literature. J Clin Ultrasound 2007;35: 284-288.

21 Machida $\mathrm{T}$, Takahashi $\mathrm{T}$, Itoh $\mathrm{T}$, et al. Reactive lymphoid hyperplasia of the liver: a case report and review of literature. World J Gastroenterol 2007;13: 5403-5407.

22 Park HS, Jang KY, Kim YK, et al. Histiocyte-rich reactive lymphoid hyperplasia of the liver: unusual morphologic features. J Korean Med Sci 2008;23:156-160.

23 Lin E. Reactive lymphoid hyperplasia of the liver identified by FDG PET. Clin Nucl Med 2008;33:419-420.

24 Katayanagi K, Terada T, Nakanuma Y, et al. A case of pseudolymphoma of the liver. Pathol Int 1994;44:704-711.

25 Kubota T, Moritani S. High incidence of autoimmune disease in Japanese patients with ocular adnexal reactive lymphoid hyperplasia. Am J Ophthalmol 2007;144:148-149.

26 de Diego J, Berridi D, Saracibar N, et al. Cutaneous pseudolymphoma in association with molluscum contagiosum. Am J Dermatopathol 1998;20:518-521.

27 Sato S, Masuda T, Oikawa H, et al. Primary hepatic lymphoma associated with primary biliary cirrhosis. Am J Gastroenterol 1999;94:1669-1673.

28 Loddenkemper $\mathrm{C}$, Longerich $\mathrm{T}$, Hummel $\mathrm{M}$, et al. Frequency and diagnostic patterns of lymphomas in liver biopsies with respect to the WHO classification. Virchows Arch 2007;450:493-502.

29 Baumhoer D, Tzankov A, Dirnhofer S, et al. Patterns of liver infiltration in lymphoproliferative disease. Histopathology 2008;53:81-90. 